\title{
Las comisiones parlamentarias de investigación: “El accidente de la Línea 1"
}

Àlvar Peris Blanes

Universitat de València

\section{Referencia de este artículo}

Peris Blanes, Àlvar (2020). Reseña de Las comisiones parlamentarias de investigación: "El accidente de la Línea 1". En adComunica. Revista Científica del Estrategias, Tendencias e Innovación en Comunicación, $\mathrm{n}^{0} 20$, Castellón: Universitat Jaume I, 395-400. DOI: http://dx.doi.org/10.6035/2174-0992.2020.20.20.

Las comisiones parlamentarias de investigación: "El accidente de la Línea 1"

Gavaldà Roca, Josep V.

Pellisser Rossell, Nel·lo (2019).

Valencia: Tirant Humanidades.

Después de más trece años de espera, finalmente un tribunal ha condenado a un año y diez meses de prisión, y tres de inhabilitación para el ejercicio de funciones directivas relacionadas con la seguridad ferroviaria, a cuatro exdirectivos de Ferrocarrils de la Generalitat Valenciana (FGV) por el accidente que tuvo lugar en la Línea 1 del metro de València el 3 de julio de 2006, en el que murieron 43 personas y otras 47 fueron heridas. Los cuatro acusados reconocieron delante de la jueza que no se pusieron todas las medidas de seguridad necesarias para evitar el siniestro en una línea cuyo mantenimiento era manifiestamente mejorable. Entre otras consideraciones, y de acuerdo con la sentencia, la simple instalación de una baliza previa hubiera permitido controlar la velocidad de los convoyes y neutralizar el riesgo de descarrilamiento y vuelco de los trenes. En el mismo fallo 
judicial se absolvió de este delito a otros cuatro exdirectivos de FGV, entre ellos a la exDirectora Gerente Marisa Gracia.

Este fue el acuerdo al que llegaron la Fiscalía y las partes unos días antes del inicio del juicio oral, que debería haber comenzado a finales de enero de 2020 y que tenía previsto alargarse durante los siguientes seis meses. Un acuerdo que la acusación particular, personalizada en la Asociación de Víctimas del Metro 3 de Julio (AVM3J), recibió con alivio y con orgullo, a partes iguales, habida cuenta que por fin quedaba demostrado aquello por lo que había luchado desde su nacimiento justo un mes después de la tragedia, esto es, que hubo responsabilidad penal en el accidente a pesar del criterio de la jueza instructora, que archivó la causa hasta en tres ocasiones, y siempre consideró que el exceso de velocidad fue la única causa y el maquinista el único responsable del descarrilamiento acaecido en una curva próxima a la estación de Jesús en aquel fatídico mes de julio. El hecho de que los acusados no vayan a prisión es coherente con lo expresado en numerosas ocasiones por la Asociación, que volvió a recordar su exigencia de justicia, que no de venganza.

La excepcionalidad en el recorrido judicial de este caso no se hubiera podido producir, seguramente, sin atender a su historia parlamentaria, cuya singularidad tampoco se queda atrás. Por primera vez en la historia de la democracia española, un parlamento, las Cortes valencianas, tuvo que celebrar dos comisiones parlamentarias, con diez años de distancia entre una y otra, para dilucidar las posibles responsabilidades políticas derivadas de un mismo asunto. El resultado fueron dos Dictámenes contradictorios, suponiendo el segundo una enmienda a la totalidad del primero, algo ciertamente inusual. Precisamente, al estudio de estas dos comisiones de investigación se dedica este trabajo de Gavaldà Roca y Pellisser Rossell, profesores de Comunicación Audiovisual de la Universitat de València, cuyo esfuerzo y meticulosidad a la hora de abordar los procedimientos activados para su realización, la configuración de las listas de comparecientes y la documentación puesta a disposición de los parlamentarios para el ejercicio del control político es, sin lugar a dudas, encomiable. A través del análisis discursivo propuesto se diseccionan y descubren, a veces con horror, las tácticas comunicativas, las estrategias argumentativas y los ejes temáticos que los protagonistas desplegaron en esta singular historia contada en dos partes, cada una de las cuales contó con unas «reglas de juego», si utilizamos el sentido conferido por Wittgenstein, diametralmente opuestas.

Como no podía ser de otro modo, el libro, que se estructura a partir de once capítulos, más sus correspondientes anexos, dedica una especial atención a la gestación y ejecución de la primera comisión, que se desarrolló prácticamente en un mes, desde el 14 de julio de 2006, cuando se celebró el Pleno de creación de la misma sólo con los votos del PP, hasta el 11 de agosto, cuando se aprobó el Dictamen preceptivo, que de nuevo contó únicamente con los votos favorables 
del Grupo Parlamentario Popular. El informe final afirmaba sin ambages que el accidente fue «inevitable e imprevisible», y volcaba toda la responsabilidad en el maquinista fallecido y en el exceso de velocidad, en coincidencia con lo expuesto por los directivos de FGV y los responsables políticos del gobierno, con el Presidente Camps a la cabeza.

Era lo esperado en una Comisión que el Grupo Popular diseñó a su medida, obstaculizando en todo momento el trabajo de la oposición y negando, a su vez, que dicha Comisión cumpliera con el principal cometido para el que fue puesta en marcha, como era la rendición de cuentas políticas, del poder ejecutivo y de la empresa pública directamente implicada en el siniestro. Aprobación de un calendario de comparecencias inadmisible; documentación negada a la oposición, incluidos los informes del Ministerio de Fomento sobre seguridad; vetos a expertos y técnicos propuestos por los partidos de la oposición mientras el PP elegía a 27 de los 32 comparecientes; destrucción de pruebas, como el borrado de la caja negra o la eliminación de informes sindicales advirtiendo sobre el deficiente estado de conservación de la Línea 1; e incluso mala praxis en los informes forenses. El Grupo Popular, que cerraba los turnos en su condición de grupo mayoritario, meditó bien el reparto de los tiempos y las modalidades de respuesta, ya que impuso la respuesta «conjunta», lo que favoreció las omisiones y que los comparecientes pudieran declarar lo más favorable para sus intereses.

Todo valió para salir indemnes políticamente de un trágico suceso que los dirigentes populares trataron de silenciar agilizando las indemnizaciones a las familias de las víctimas y prometiendo una Ley de Seguridad Ferroviaria cuya aprobación definitiva no llegó hasta el 26 de marzo de 2018, ya con un gobierno progresista en la Generalitat. No es casualidad que, a pesar de lo subrayado en el Dictamen, FGV empezara a instalar balizas de seguridad en todas las curvas sospechosas, especialmente en el túnel de la Línea 1. Justo aquello que se había demandado en infinidad de ocasiones por parte de los sindicatos desde que en septiembre de 2005 tres convoyes colisionaran gravemente en otro tramo de esta misma línea causando heridas a varias personas, entre ellas un conductor a quien se le tuvo que amputar una pierna. Un comportamiento «bochornoso», como lo han calificado los autores de este trabajo, quienes tuvieron que recurrir a la web Oresponsables, creada años después del accidente por la productora valenciana Barret Films, para acceder a los vídeos de las comparecencias y otros documentos, en una muestra más de la falta de transparencia y de respeto hacia las víctimas y los derechos de los ciudadanos que caracterizó la citada Comisión.

El desprecio con el que trató el Grupo Parlamentario Popular a un órgano facultado para el control político obligó a las Cortes Valencianas a proponer una segunda comisión de investigación, que se inició unos días después de la inauguración de la novena legislatura, el 3 de julio de 2015, y se cerró con la aprobación del Dictamen un año después, el 13 de julio de 2016. Si nos atenemos al nombre, sólo 
hubo una pequeña diferencia entre la primera y la segunda, y fue el añadido de «especial», que da cuenta de lo insólito de la situación. Pero lo cierto es que las dos comisiones no tuvieron nada que ver, como explican detalladamente los autores de la investigación. Para empezar, en el resultado del informe. En esta ocasión, la Comisión señaló que hubo responsabilidad política en la tragedia y que fueron trece las personas implicadas: cuatro miembros del poder ejecutivo y uno del legislativo, seis directivos de FGV y dos directivos de Radiotelevisión valenciana (RTVV), cuyo papel en la gestión de la información durante el día del accidente y en los días, meses y años posteriores se vio altamente comprometida.

A continuación, porque la segunda Comisión se pudo desarrollar con las máximas garantías procedimentales, algo absolutamente imprescindible. Entre otras cosas, se apostó por una interacción discursiva mucho más directa, donde el compareciente debía responder a cada una de las preguntas por separado, en una práctica muy similar al interrogatorio judicial. En algunos comparecientes se reeditaron las omisiones, las reticencias y las inexactitudes, incluso las falsedades, pero afortunadamente tuvieron que adaptarse a unas reglas parlamentarias muy distintas que les obligaron a responder, aunque fuera a desgana. De hecho, el «falso testimonio» llegó a ser denunciado en sede judicial, habida cuenta que las comisiones parlamentarias están amparadas por el artículo 502.3 del Código Penal. Y finalmente, porque los autores, ahora sí, pudieron realizar la presente investigación con los documentos utilizados por la comisión.

Parecía que con el segundo dictamen se cerraba la trayectoria parlamentaria de este accidente. Pero no iba a ser así. Uno de los responsables políticos señalados en el mismo, el exDirector de Recursos Humanos de FGV, presentó recurso ante el Tribunal Constitucional (TC) por considerar vulnerado su derecho al honor. El recurso argumentaba que las Cortes Valencianas habían realizado un juicio paralelo y no estaban legitimadas para llevar a cabo imputaciones o determinaciones procesales sobre la autoría de comportamientos ilícitos. La sentencia, dictada en diciembre de 2018, falló a su favor y supuso una enmienda a la resolución aprobada por el parlamento valenciano que obliga a revisar la regulación de las comisiones de investigación en España. Esta cuestión es uno de los objetivos fundamentales del trabajo de Gavaldà Roca y Pellisser Rossell, y a ella dedican algunas de las páginas más sugestivas de todo el volumen.

A pesar de estar tuteladas penalmente, las comisiones parlamentarias de investigación, a diferencia de países europeos como Alemania y Portugal, tienen muy mermada su capacidad de ejercer la labor de control político de forma efectiva. De modo que, finalmente, sólo una instancia judicial, y las urnas, en su defecto, pueden declarar la responsabilidad política de un empleado o funcionario público. Además, se da la paradoja de que un órgano concebido para la rendición de cuentas del poder ejecutivo otorgue a las mayorías parlamentarias maniobrabilidad para decidir a su antojo. Eso deja a las comisiones de investigación en una posi- 
ción de vulnerabilidad manifiesta, expuestas a los desmanes de comparecientes sin escrúpulos. Para tratar de paliar este déficit, y teniendo en cuenta que el debate parlamentario constituye una referencia primordial en la articulación del espacio público democrático, los autores defienden la necesidad de elaborar un protocolo que les permita ser más eficaces, adjudicándoles poderes para levantar acta de las contradicciones entre los testimonios y para hacer un uso más eficiente de la documentación, que debería ser pública. Con mayor transparencia y la posibilidad de realizar auditorías independientes, como recomienda la Unión Europea desde 2004, las comisiones parlamentarias podrían contribuir decisivamente a incrementar la calidad de la democracia española en un momento en el que hay previstas algunas comisiones de gran impacto social, como las de los accidentes del avión Spanair en Barajas y del tren Alvia en Angrois, Galicia.

Otro de los aspectos más destacados del libro desde el punto de vista del análisis del discurso es la atención especial que presta al papel desempeñado en esta historia por los consultores de comunicación contratados por FGV, así como por RTVV. Esta colaboración arrancó antes del accidente, cuando FGV se empecinó en gastar un dinero que no tenía, pues estaba colapsada financieramente, en una empresa de eventos, la valenciana HM\&Sanchis, básicamente dedicada a la agitación publicitaria permanente, que a su vez subcontrató a una compañía madrileña de la que se sabe más bien poco, Mirror Imagen Profesional, para que se encargara de la elaboración de informes mensuales que cuantificaran, al más puro estilo de la administrative research, la presencia en forma de impactos de la empresa pública en los medios. Para llevar a cabo su cometido no reparó en implementar campañas de opinión tóxicas y utilizar tácticas de lobby para premiar y castigar a los medios «amigos» y a los «hostiles», según fuera la tendencia de sus informaciones, en un momento clave en el sistema comunicativo valenciano, pendiente del reparto de las licencias de Televisión Digital Terrestre por parte del Gobierno autonómico. El siniestro truncó los planes propagandísticos, pero no el intervencionismo de HM\&Sanchis, que durante la primera Comisión y los años siguientes tuvo el penoso encargo de adoctrinar, aleccionar, asesorar y formar a los comparecientes propuestos por el PP para que se ajustaran a la versión oficial, como se supo tiempo después gracias a la denuncia de un arrepentido.

En vez de invertir en una infraestructura ferroviaria que incluso la exDirectora Gerente había calificado de «obsoleta», FGV prefirió contratar hasta 2012 una empresa de marketing, en el marco de un modelo de publicidad institucional de partido a cargo del contribuyente. Como indican los autores de este trabajo, todavía quedan por conocer detalles del contrato y de las cantidades facturadas. La confusión entre ser una empresa pública, o trabajar para ella, y el partido también se pudo observar con nitidez en el caso de RTVV, que ofreció un manual de manipulación informativa en los días posteriores al accidente. En plena semana del V Encuentro Mundial de la Familia, con visita del Papa Benedito XVI a València incluida, y a 
cuya preparación el PP se había volcado en «cuerpo y alma», los servicios informativos de la cadena pública actuaron con una parcialidad inusitada, siempre en consonancia con el discurso promovido por el Consell de la Generalitat y FGV. Los responsables de RTVV siempre negaron los hechos y reivindicaron el trabajo riguroso, plural y objetivo realizado aquellos días. Sin embargo, su línea informativa fue tan escandalosa que la AVM3J presentó una denuncia ante el Síndic de Greuges, aunque con poco éxito, pues fue despachada al poco tiempo dando la razón a los medios públicos valencianos aún a riesgo de comprometer a la institución.

De todos modos, la censura practicada por RTVV no se limitó a aquellas semanas, sino que continuó durante años. Parece inaudito pero los portavoces de la AVM3J acudieron por primera vez a un plató de la cadena pública el día de su cierre en noviembre de 2013, cuando los trabajadores tomaron las riendas de la programación. En ese momento, la opinión pública en torno al accidente había variado sustancialmente. El trabajo infatigable de los medios «hostiles», la creación de la web Oresponsables y la realización de un documental por parte de Barret Films y, sobre todo, el programa Salvados, de La Sexta, dedicado a la tragedia del metro, consiguieron que la sociedad valenciana finalmente se pusiera del lado de las familias de las víctimas y acudiera masivamente a las concentraciones que cada mes se convocaban en la Plaza de la Virgen de València exigiendo unas responsabilidades que al final se han sustanciado judicialmente.

Con la sentencia, las familias de las víctimas podrán finalmente descansar, cerrando la etapa seguramente más vergonzosa y mezquina de cuantas tuvieron lugar durante la etapa del PP en el gobierno valenciano. Para salvaguardar su ineptitud y arrogancia, el Gobierno de Camps arrastró al lodo al Grupo Parlamentario Popular, pero también a instituciones públicas como FGV, RTVV y la Sindicatura de Greuges. Para el infausto recuerdo de todos quedará el trato humillante que dispensaron a la AVM3J, a quienes nunca recibieron ni pidieron disculpas, en una falta de empatía incalificable (en el 2011 serían recibidos por el Presidente Fabra, también del PP, en una suerte de acto de desagravio fallido). Poco o nada de eso se vio en aquellos años, como se constata en esta clarividente investigación, que supone un acercamiento novedoso al análisis comunicativo de las comisiones parlamentarias que puede despertar interés en públicos muy diversos, teniendo en cuenta que nos devuelve una imagen de un pasado reciente de abusos por parte del poder político y, en parte, también del judicial, que no debería tener cabida en cualquier sociedad moderna y democrática que se precie. 